\title{
Meconium Dependence of Bowel Damage in Gastroschisis
}

\author{
By Jorge Correia-Pinto, Marta L. Tavares, Maria J. Baptista, Tiago Henriques-Coelho, José Estevão-Costa, \\ Alan W. Flake, and Adelino F. Leite-Moreira \\ Porto, Portugal and Philadelphia, Pennsylvania
}

\begin{abstract}
Background/Purpose: Increasing evidence of physiologic in utero defecation supports the hypothesis that bowel damage in gastroschisis may be meconium dependent. In this study, the author investigated the role of meconium on parameters of bowel damage in a fetal rat model of gastroschisis.
\end{abstract}

Methods: Pregnant rats underwent laparotomy at 18 1/2 days gestational age (GA). There were 4 experimental groups of 11 fetuses each; the $G_{M}$ group consisted of fetuses with isolated gastroschisis and was considered to have moderate meconium contamination of the amniotic fluid (MCAF); the $\mathrm{G}_{\mathrm{L}}$ group consisted of fetuses with gastroschisis and anal ligation, performed to prevent MCAF; the $\mathrm{G}_{\mathrm{H}}$ group consisted of fetuses with gastroschisis and colon perforation, performed to increase MCAF; and the Sham group consisted of sham operated controls. All fetuses were harvested by cesarean section at $211 / 2$ days GA, and the fetal intestine was assessed for peel, intestinal length, intestinal weight per unit length, and histologic appearance.

Results: The authors achieved the following fetal survival rates: $G_{M}$ group, $91 \%$ (10 of 11 ); $G_{L}$ group, $78 \%$ (7 of 9 , the ligation was not successful in 2 fetuses); $G_{H}$ group, $82 \%$ (9 of 11). Sham group, $100 \%$ (11 of 11). Intestinal length was decreased in fetuses with gastroschisis, and this reduction was related directly to the grade of MCAF (Sham, 18.4 \pm 0.6 ; $\left.\mathrm{G}_{L}, 11.5 \pm 0.5 ; \mathrm{G}_{\mathrm{M}}, 10.2 \pm 0.6 ; \mathrm{G}_{\mathrm{H}}, 9.1 \pm 0.6 \mathrm{~cm} ; P<.01\right)$. In contrast, intestinal weight per unit length increased in fetuses with gastroschisis, and this increase was related directly to the grade of MCAF (Sham, $7.8 \pm 0.5 ; \mathrm{G}_{\mathrm{L}}, 9.4 \pm 0.5$; $\left.\mathrm{G}_{\mathrm{M}}, 11.3 \pm 0.5 ; \mathrm{G}_{\mathrm{H}}, 16.9 \pm 0.7 \mathrm{mg} / \mathrm{cm} ; P<.01\right)$. In comparison with the $G_{M}$ group, the degree of peel coverage and bowel adherence were increased markedly in the $G_{H}$ group, whereas the fetuses of the $G_{L}$ group had neither peel nor bowel adherence.

Conclusions: All bowel damage parameters were affected by MCAF supporting the hypothesis that bowel damage in gastroschisis is at least partially dependent on meconium exposure. Further research is required to clarify other factors that contribute to bowel damage and to identify risk factors that may allow prenatal identification of severely affected fetuses.

J Pediatr Surg 37:31-35. Copyright $\odot 2002$ by W.B. Saunders Company.

INDEX WORDS: Gastroschisis, rat, fetal surgery, meconium, bowel damage.
I

N RECENT YEARS, the clinical outcome of gastroschisis has improved considerably. However, bowel damage still is responsible for significant neonatal morbidity and even mortality. Improved understanding of the pathogenesis of bowel injury is required for rational perinatal strategies to evolve. It has been accepted generally that bowel damage results from prolonged contact with amniotic fluid, particularly late in gestation. ${ }^{1}$ The pathophysiologic mechanism of bowel damage has been postulated to be related to hypotonicity of the amniotic fluid caused by fetal urination, ${ }^{2}$ meconium contamination of the amniotic fluid, ${ }^{3}$ or ischemia secondary to constriction of the bowel at the abdominal wall defect. ${ }^{4}$

During the last decade, the pathophysiologic involvement of urine in bowel damage has been refuted. ${ }^{5}$ At the same time, there is increasing evidence that in utero defecation normally occurs ${ }^{6}$ suggesting that bowel damage in gastroschisis may be meconium dependent. Supporting this hypothesis are studies in which instillation of diluted human meconium into the abdominal cavity of adult rats ${ }^{7}$ or the amniotic fluid of chick embryos with experimental gastroschisis ${ }^{3}$ induces intestinal abnormalities that resemble the histologic changes typically seen in human gastroschisis. Although suggestive of a role for meconium in the pathophysiology of bowel damage in gastroschisis, these studies were somewhat artificial and did not examine other parameters of bowel damage.

In the current study, multiple parameters of bowel damage were assessed in the fetal rat model of gastroschisis $^{8}$ with graded contamination of the amniotic fluid by meconium. Our results strongly support the importance of meconium exposure in the pathophysiology of bowel injury in gastroschisis.

From the Departments of Physiology and Pediatric Surgery, Faculty of Medicine, Porto, Portugal, and The Children's Institute for Surgical Science, The Children's Hospital of Philadelphia, Philadelphia, PA.

The Portuguese Section of Neonatology awarded this work. This work was supported by a grant from FCT (PRAXIS/C/SAU/11301/98) cosponsored by FEDER, through Unidade $1 \& D$ Cardiovascular no. 51/94/FCT, Portugal.

Address reprint requests to Jorge Correia-Pinto, MD, Serviço de Fisiologia, Faculdade de Medicina da Universidade do Porto, Al Prof Hernâni Monteiro, 4200-319 Porto, Portugal.

Copyright (C) 2002 by W.B. Saunders Company

0022-3468/02/3701-0006\$35.00/0

doi:10.1053/jpsu.2002.29422 


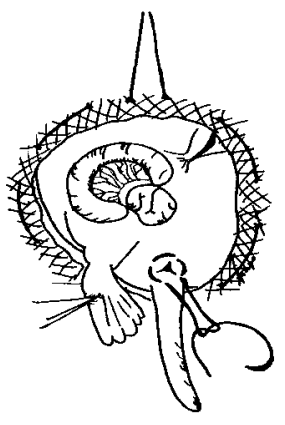

$\mathbf{G}_{\mathbf{L}}$

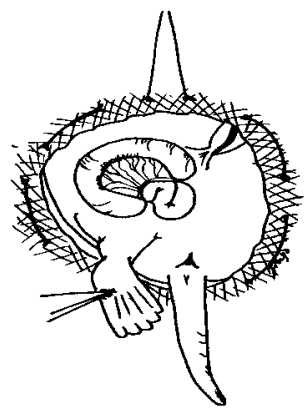

$\mathbf{G}_{\mathbf{M}}$

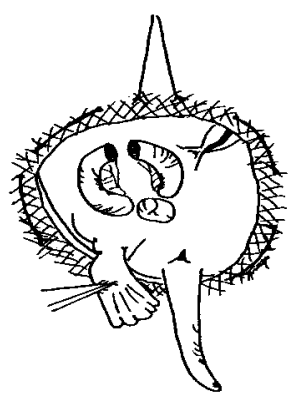

$\mathbf{G}_{\mathbf{H}}$
Fig 1. Schematic representation of the surgical procedures performed on the experimental groups.

\section{MATERIALS AND METHODS}

All experimental protocols were reviewed and approved by the Institutional Animal Care and Use Committee and followed guidelines set forth in the National Institutes of Health Guide for the Care and Use of Laboratory Animals.

\section{Experimental Model}

Female Wistar rats were obtained from a commercial breeder (225 g; Criffa, S.A., Barcelona, Spain). Animals were mated and the females were checked daily for introital plugging. The day of plugging was defined as gestational day 0 for time dating. The pregnant rats were kept in individual cages and maintained under 12 hours-light/12 hoursdark cycling conditions. On day 18.5 of gestation (term, 22 days) anesthesia was induced by inhalation of sevoflurane (Sevorane, Abbott Laboratories, Alverca, Portugal) supplemented by intraperitoneal sodium pentobarbital $(15 \mathrm{mg} / \mathrm{kg})$ maintaining adequate depth of anesthesia with inhaled sevoflurane as monitored by inhibition of the corneal reflex.

Using sterile technique, a 3-cm midline laparotomy was performed and the bicornuate uterus exposed. A hysterotomy was performed by placement of a 6-0 Prolene purse-string suture incorporating the amniotic membranes followed by a 3-mm incision placed within the purse-string overlying the right hind limb. During the entire surgical procedure, the uterus and exposed fetus were moistened continually with prewarmed sterile saline solution $\left(37^{\circ} \mathrm{C}\right)$. The right hind limb then was exteriorized, and, under a stereo dissection microscope (Leica, Wild M651.MS-D, Herbrugg, Switzerland) an incision was performed on the fetal lower right abdominal quadrant (16×, magnification). Careful wall dissection was performed to avoid damage of the liver and the umbilical vessels. Exteriorization of bowel loops was achieved by gentle pressure on the lower fetal abdomen with evisceration of the intestine facilitated by traction with a smooth cotton patty (Codman, Johnson \& Johnson, Lisboa, Portugal). Control fetuses underwent only leg manipulation. The right hindlimb was returned to the amniotic space, and the uterine incision was closed with the 6-0 purse-string suture after the uterine cavity had been filled with a prewarmed saline solution. The exposed uterus was bathed with ritodrine for tocolysis (10 $\mathrm{mg} / \mathrm{mL}$, Prepar, Solvay, Portugal), and maternal laparotomy was closed in 2 layers with a continuous 4-0 silk suture. Fetuses were harvested by cesarean at 21.5 days' gestational age. Eviscerated organs were identified. Fetuses were weighed and killed. The eviscerated intestine was evaluated for peel and bowel adhesions. The intestinal tract was removed from pylorus to rectum. It was weighed on a precision balance (SBC 21; Scaltec Instruments, Heeligeesdadt, Germany), and its length was measured with a millimetric ruler. To evaluate tissue edema we calculated the intestinal weight per unit length.

\section{Experimental Groups}

Eleven dams were operated on with 4 fetuses per dam manipulated. In each dam 1 fetus underwent creation of isolated gastroschisis $\left(G_{M}\right.$ group), 1 underwent creation of gastroschisis with anal ligation with a pursestring suture $\left(\mathrm{G}_{\mathrm{L}}\right.$ group), 1 underwent creation of gastroschisis and colon perforation $\left(\mathrm{G}_{\mathrm{H}}\right.$ group), and 1 fetus had leg manipulation alone (sham group) for a total of 11 fetuses per group (Fig 1). The group with isolated gastroschisis was considered to have moderate contamination $\left(\mathrm{G}_{\mathrm{M}}\right.$ group), the group with gastroschisis and colon perforation to have high contamination $\left(\mathrm{G}_{\mathrm{H}}\right.$ group), and the group with gastroschisis and anal ligation to have low, if any, contamination $\left(\mathrm{G}_{\mathrm{L}}\right.$ group).

\section{Tissue Preparation}

The eviscerated intestine from all groups was fixed in $10 \%$ formalin and paraffin embedded for routine histology. Each paraffin block was numbered randomly, allowing blinded morphometric analysis. After embedding, 10- $\mu \mathrm{m}$ transverse sections of the intestine were stained for routine histology with Harris hematoxylin and counter-stained with eosin. Histologic evaluation of the intestinal wall focused on assessment of serosal thickening and the presence or absence of an inflammatory infiltrate.

\section{Data Analysis}

All data are presented as mean \pm SEM. The data sets passed on Kolmogoronov-Smirnov test for normality. Statistical analysis then was performed with the 1-way analysis of variance (ANOVA) test, and the Student-Newman-Keuls test was used for posttest analysis when significant differences were detected. Statistical significance was set at $P<.05$.

\section{RESULTS}

Maternal survival rate was $100 \%(\mathrm{n}=11)$. We manipulated 44 fetuses (11 for each group) with the following survival rates: sham group, $100 \%$ (11 of 11$) ; \mathrm{G}_{\mathrm{M}}$ group, $91 \%$ (10 of 11 ); $\mathrm{G}_{\mathrm{L}}$ group, $78 \%$ (7 of 9 , the ligation was not successful in 2 fetuses); $\mathrm{G}_{\mathrm{H}}$ group, $82 \%$ (9 of 11). Body weight was decreased uniformly and significantly in fetuses with gastroschisis when compared with the sham group $(3.95 \pm 0.16 v 4.59 \pm 0.18 \mathrm{~g}$; $P<.05)$. Meconium staining of the amniotic fluid was clearly evident in the $\mathrm{G}_{\mathrm{H}}$ group. In the $\mathrm{G}_{\mathrm{L}}$ group, the bowel was dilated slightly with bilious content. On gross 

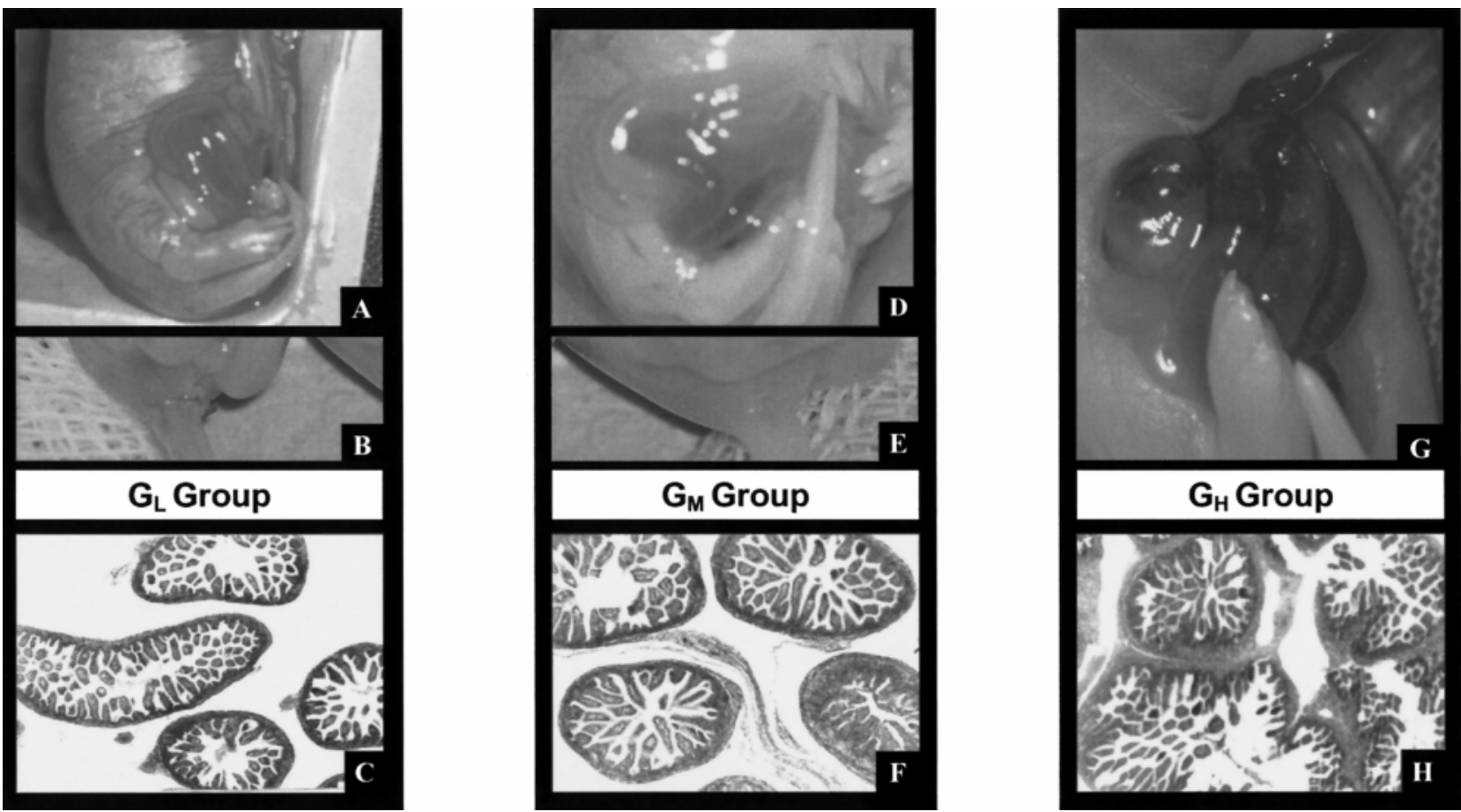

Fig 2. Representative examples of the experimental results. Fetal rat from $G_{L}$ group: (A) macroscopic aspect at which bowel loops appear nondilated and without significant peel (original magnification, $\times 6$ ); (B) successful anal ligation; (C) microscopic aspect shows bowel wall without significant edema and no bowel adherence (original magnification, $\times 40$ ). Fetal rat from $G_{M}$ group: (D) macroscopic aspect at which bowel loops appear with moderate degree of peel and no significant dilatation (original magnification, $\times 10) ;(E)$ no anal ligation; (F) microscopic aspect shows bowel wall with mild edema but without significant bowel adherence (original magnification, $\times 40$ ). Fetal rat from $G_{H}$ group: $(G)$ macroscopic aspect at which it is clear severe bowel damage with significant peel and dilatation (original magnification, $\times 10)$; $(H)$ microscopic aspect at which significant bowel wall edema and bowel adherence are evident (original magnification, $\times 40$ )

examination, some degree of peel coverage and bowel adherence was present in the $\mathrm{G}_{\mathrm{M}}$ group, but both were markedly increased in $G_{H}$ group. In contrast, the $G_{L}$ group had neither peel nor bowel adherence (Fig 2). Intestinal length was decreased significantly in all groups of fetuses with gastroschisis, and this reduction was related directly to the grade of amniotic meconium contamination (Fig 3). In contrast, intestinal weight per unit length increased in fetuses with gastroschisis, and this increase was related directly to the grade of amniotic meconium contamination (Fig 4). In comparison with the $\mathrm{G}_{\mathrm{M}}$ group, the histologic examination in the $\mathrm{G}_{\mathrm{H}}$ group showed significant serosal thickening and inflammatory infiltrate, whereas in the $\mathrm{G}_{\mathrm{L}}$ group these findings were blunted (Fig 2).

\section{DISCUSSION}

Bowel damage is the primary cause of morbidity and mortality associated with gastroschisis. The goal of perinatal management is to avoid or prevent the bowel damage commonly observed in gastroschisis. ${ }^{9}$ Improved understanding of the pathogenesis of bowel injury is,

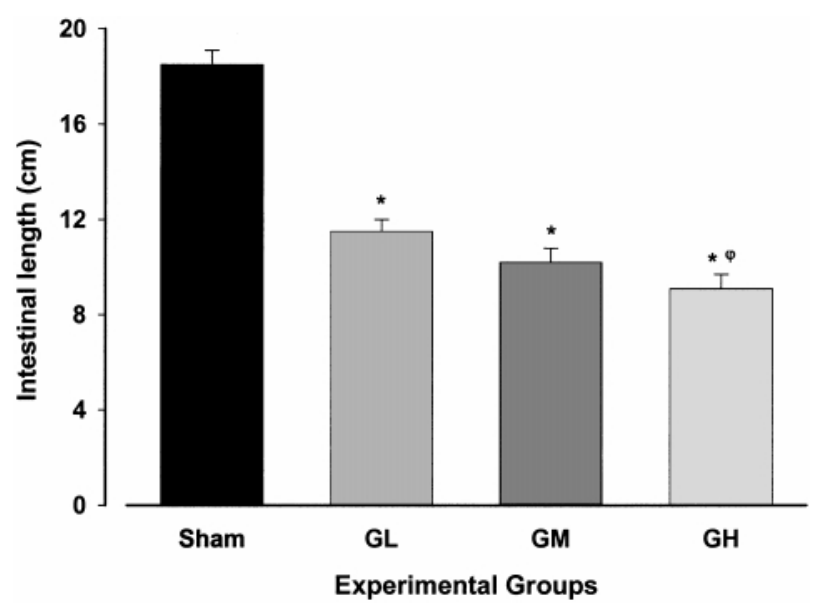

Fig 3. Intestinal length $(\mathrm{cm})$ was compared among the group of fetuses without gastroschisis (sham), fetuses with gastroschisis and anal ligation $\left(G_{L}\right)$, fetuses with only gastroschisis $\left(G_{M}\right)$, and fetuses with gastroschisis and colon perforation $\left(G_{H}\right)$. Increasing meconium contamination was associated with progressive intestinal shortening. $P<.01$, indicated significance: * versus sham; $\varphi$ versus $\mathrm{G}_{\mathrm{L}}$. 


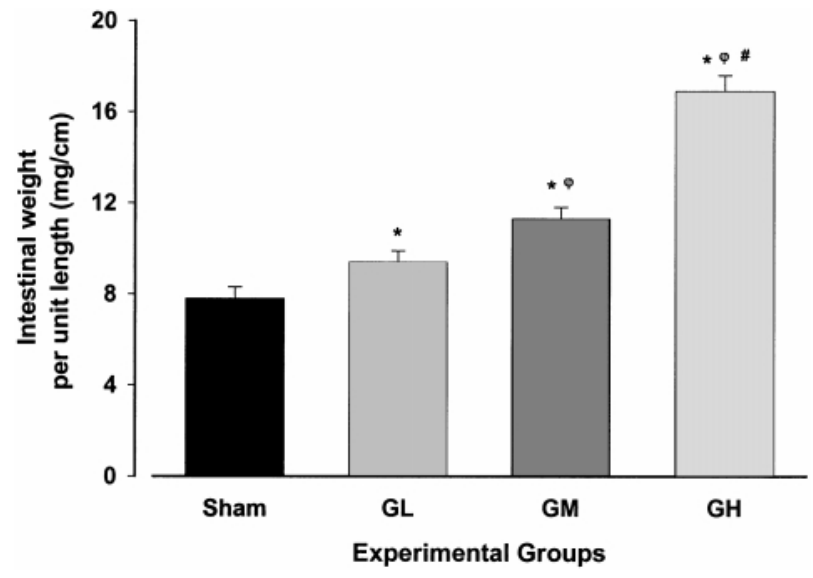

Fig 4. Intestinal weight per unit length $(\mathrm{mg} / \mathrm{cm})$ was compared among the group of fetuses without gastroschisis (sham), fetuses with gastroschisis and anal ligation $\left(\mathrm{G}_{\mathrm{L}}\right)$, fetuses with only gastroschisis $\left(G_{M}\right)$, and fetuses with gastroschisis and colon perforation $\left(G_{H}\right)$. Increasing meconium contamination was associated with progressive increase of the Intestinal weight per unit length. $P<.01$ indicated significance: * versus sham; $\varphi$ versus $\mathrm{G}_{\mathrm{L}}$; \# versus $\mathrm{G}_{\mathrm{M}}$.

therefore, required for rational perinatal strategies to evolve.

Traditionally, in utero meconium passage was believed to occur only during fetal distress. Recently, Ciftci et $\mathrm{al}^{6}$ challenged this idea showing that meconiumstained amniotic fluid is not related to meconium passage after distress, but reflects impaired clearance of amniotic fluid, which already has meconium caused by in utero physiologic defecation. The presence of intestinal enzymes in the amniotic fluid of healthy fetuses and its absence in fetuses with intestinal obstruction also supports the idea that meconium passage during fetal life is a normal physiologic event. ${ }^{10-12}$ Proximal intestinal dilatation in fetuses with colonic atresia or anorectal malformation also favors this theory.

In the current study, we tested the hypothesis that bowel damage in gastroschisis is meconium dependent in the fetal rat model of gastroschisis. We chose this model because it has various advantages when compared with other experimental models of gastroschisis. ${ }^{8}$ The fetal rat model has unusually high maternal and fetal survival rates that we reproduced in the current study. In addition, the rat model is the only one that enables littermatematched controls. In fact, to our knowledge, this is the first study in which various experimental groups with gastroschisis were created under the same maternal environment.

Increased meconium contamination of amniotic fluid induced a pronounced increase in peel coverage, bowel adherence, and a significant decrease in intestinal length. Prevention of meconium contamination with anal ligation markedly prevented peel development and reduced bowel adherence significantly as well as tissue edema. It did not, however, completely prevent bowel shortening relative to controls. Bowel shortening was the parameter of bowel damage least affected by meconium exposure in this study. These results suggest that meconium is involved on the pathophysiology of bowel damage in gastroschisis, although we can not exclude that other factors are implicated as well. Bowel damage in gastroschisis may have, therefore, a similar pathophysiology with bowel damage observed in meconium peritonitis. ${ }^{13}$

The assumption that damage from amniotic fluid depends on the extent of meconium contamination may help to explain the findings of Langer et al. ${ }^{1}$ These investigators showed that bowel damage in gastroschisis was dependent on amniotic fluid contact, and that most of the damage occurred late in gestation. In utero defecation also is gestational age dependent and becomes more prevalent the last few weeks of gestation. ${ }^{6,10}$

The observation that bowel damage in fetuses with gastroschisis strongly correlates with amniotic fluid meconium content may help to explain the results of some human studies of gastroschisis. For instance, Morrison et $\mathrm{al}^{14}$ showed that human fetal gastroschisis is associated with an acute inflammatory exudate, composed predominantly of activated neutrophils with markedly elevated interleukin 8 levels in the amniotic fluid. It has been shown that interleukin 8 is present in human meconium in large concentrations and that it is a powerful inducer of neutrophil chemotaxis. ${ }^{15}$ Thus, we can speculate that the inflammatory exudate characteristic of the amniotic fluid in fetuses with gastroschisis may be caused by the chemotactic cytokine interleukin 8 , which is present in meconium. These findings may have clinical ramifications for the development of antiinflammatory treatments aimed at inhibition of neutrophil influx and activation in the amniotic fluid to prevent bowel damage in fetuses with gastroschisis.

Taking into account the results of this study, the deleterious effects of intraamniotic meconium on gastroschisis bowel could be prevented by lowering the intraamniotic meconium concentration. This can be achieved by 2 methods depending on amniotic fluid volume: amniotic fluid can be withdrawn and replaced by physiologic saline (amniotic fluid exchange) in cases of normal amniotic fluid volume ${ }^{16,17}$ or physiologic saline may be instilled into the amniotic fluid (amnioinfusion) in cases of oligohydramnios. ${ }^{18-21}$ Whereas amniotic fluid exchange works by partially replacing the meconium bearing amniotic fluid with a solution devoid of meconium, amnioinfusion could prevent intestinal damage in gastroschisis by diluting the amniotic fluid. Before this becomes accepted clinical practice, however, we need prenatal criteria to identify the most severely affected fetuses. 
We have shown that all of the studied parameters of bowel damage were affected by meconium contamination of the amniotic fluid. This strongly supports at least a partial role for meconium exposure in the pathogenesis of bowel damage in gastroschisis. Further research is required to clarify other factors that contribute to bowel damage and to identify risk factors that may allow prenatal identification of severely affected fetuses.

\section{ACKNOWLEDGMENTS}

The authors thank Mrs Rosa Gonçalves and Mrs Antónia Teles from the Department of Physiology for their excellent technical support.

\section{REFERENCES}

1. Langer JC, Bell JG, Castillo RO, et al: Etiology of intestinal damage in gastroschisis II. Timing and reversibility of histological changes, mucosal function and contractility. J Pediatr Surg 25:11221126, 1990

2. Kluck P, Tibboel D, van der Kamp AWM, et al: The effect of fetal urine on the development of the bowel in gastroschisis in fetal sheep. J Pediatr Surg 9:627-632, 1974

3. Olguner M, Akgür FM, Api A, et al: The effects of intraamniotic human neonatal urine and meconium on the intestines of the chick embryo with gastroschisis. J Pediatr Surg 35:458-461, 2000

4. Langer JC, Longaker MT, Crombleholme TM, et al: Etiology of intestinal damage in gastroschisis. I: Effects of amniotic fluid exposure and bowel constriction in a fetal lamb model. J Pediatr Surg 24:992997, 1989

5. Albert A, Julia V, Morales L, et al: Role of the amniotic fluid in gastroschisis. An experimental study. J Pediatr Surg 28:656-659, 1993

6. Ciftci AO, Tanyel FC, Bingol-Kologlu M, et al: Fetal distress does not affect in utero defecation but does impair the clearence of amniotic fluid. J Pediatr Surg 34:246-250, 1999

7. Akgur FM, Ozdemir T, Olguner M, et al: An experimental study investigating the effects of intraperitoneal human neonatal urine and meconium on rat intestines. Res Exp Med 198:207-213, 1998

8. Correia-Pinto J, Tavares ML, Baptista MJ, et al: A new fetal rat model of gastroschisis: Development and early characterization. J Pediatr Surg 36:213-216, 2001

9. Correia-Pinto J, Estevão-Costa J: Prolonged intestinal exposure to amniotic fluid does not result in peel formation in gastroschisis. J Pediatr Surg 35:399, 2000 (letter)

10. Pocknee RC, Abramovich DR: Origin and levels of trypsin in amniotic fluid throughout pregnancy. Br J Obstet Gynecol 89:142-144, 1982

11. Kleijer WJ, Janse HC, Van Diggelen OP, et al: Amniotic fluid disaccharidases in the prenatal detection of cystic fibrosis. Prenat Diagn 5:135-143, 1985

12. Morin PR, Potier M, Dallaire L, et al: Prenatal detection of intestinal obstruction: Deficient amniotic fluid disaccharidases in affected fetuses. Clin Genet 18:217-222, 1980

13. Dirkes K, Crombleholme TM, Craigo SD, et al: The natural history of meconium peritonitis diagnosed in utero. J Pediatr Surg 30:979-982, 1995

14. Morrison JJ, Klein N, Chitty LS, et al: Intra-amniotic inflammation in human gastroschisis: Possible aetiology of postnatal bowel dysfunction. Br J Obstet Gynecol 105:1200-1204, 1998.

15. Beaufort AJ, Pelikan DMV, Elferink JGR, et al: Effect of interleukin 8 in meconium on in-vitro neutrophil chemotaxis. Lancet 352:102-105, 1998

16. Aktug T, Erdag G, Kargi A, et al: Amino-allantoic fluid exchange for the prevention of intestinal damage in gastroschisis: An experimental study on chick embryos. J Pediatr Surg 30:384-387, 1995

17. Aktug T, Demir N, Akgür FM, et al: Intrauterine pretreatment of gastroschisis with transabdominal amniotic fluid exchange. Obstet Gynecol 91:821-823, 1997

18. Dommergues M, Ansker Y, Aubry MC, et al: Serial transabdominal amnioinfusion in the management of gastroschisis with severe oligohydraminos. J Pediatr Surg 31:1297-1299, 1996

19. Luton D, de Lagausie P, Guibourdenche J, et al: Effect of amnioinfusion on the outcome of prenatally diagnosed gastroschisis. Fetal Diagn Ther 14:152-155, 1999

20. Luton D, de Lagausie P, Guibourdenche J, et al: Influence of amnioinfusion in a model of in utero created gastroschisis in the pregnant ewe. Fetal Diagn Ther 15:224-228, 2000

21. Sapin E, Mahieu D, Borgnon J, et al: Transabdominal amnioinfusion to avoid fetal demise and intestinal damage in fetuses with gastroschisis and severe oligohydramnios. J Pediatr Surg 35:598-600, 2000 